Article

\title{
An Analytical Method for Estimating the Maximum Penetration of DFIG Considering Frequency Stability
}

\author{
Mengqi Qing ${ }^{1, * \mathbb{D}}$, Fei Tang ${ }^{1, * \mathbb{D}}$, Fusuo Liu ${ }^{2}$, Dichen Liu ${ }^{1}$, Nianchun $\mathrm{Du}^{1}$ and Benxi Hu ${ }^{1}$ \\ 1 School of Electrical Engineering and Automation, Wuhan University, Wuhan 430072, China; \\ dichenliu@whu.edu.cn (D.L.); nianchun.du@whu.edu.cn (N.D.); hubenxi@whu.edu.cn (B.H.) \\ 2 Nanrui Group, State Grid Electric Power Research Institute, Nanjing 211111, China; \\ 1liufusuo@sgepri.sgcc.com.cn.com \\ * Correspondence: qingmengqi@whu.edu.cn (M.Q.); tangfei@whu.edu.cn (F.T.)
}

Received: 14 September 2020; Accepted: 20 November 2020; Published: 25 November 2020

\begin{abstract}
With the increasing wind power in power systems and the wide application of frequency regulation technology, the accurate calculation of the limit wind power capacity in systems is critical to ensure the stability of the frequency and guide the planning of wind power sources. This paper proposes an analytical method for calculating the maximum wind generation penetration under the constraints of frequency regulation control and frequency stability taking doubly fed induction generator as an example. Firstly, the frequency-domain dynamic model of the doubly fed induction generator is established considering the supplementary frequency proportion-differentiation control under small disturbance. The equivalent inertia time constant of the doubly fed induction generator is calculated. On this basis, the frequency response model of the power system with the consideration of wind power integration in frequency regulation control is constructed. Then, the frequency-domain analytical solution of the system frequency is obtained. Finally, with the constraint by the steady-state deviation and dynamic change rate of the system frequency, the maximum wind generation penetration is analytically solved. The accuracy of the proposed analytical calculation method for the limit value of the percentage of wind power is verified by MATLAB/Simulink.
\end{abstract}

Keywords: DFIG; frequency response model; frequency stability constraint; small-signal model; frequency control

\section{Introduction}

\subsection{Background and Motivation}

Wind power is generally regarded as the most promising renewable energy [1,2]. At present, the most widely used doubly fed induction generator (DFIG) has an excellent performance of capturing the maximum wind energy at real-time wind speed. However, its rotor speed is no longer coupled with the system frequency. The rotational kinetic energy contained in the rotor cannot be released, resulting in a drop in the inertia of the power system. The continuous increase of wind power capacity seriously threatens the stability of the frequency [3,4]. Moreover, frequency is one of the most critical factors restricting the acceptable capacity of wind power in the system $[5,6]$. For better guiding power planning and maintaining the safe and stable operation of the system, it has essential significance to estimate the maximum wind generation penetration, which is defined as the ratio of the maximum capacity of the acceptable wind power to the system capacity [7], based on the frequency constraints [8,9]. 


\subsection{Literature Review}

(1) Dynamic modeling of the power system

In order to study the limit wind power capacity from the perspective of frequency stability, the prerequisite is to develop the dynamic model of the system. The typical models describing the frequency response of the power system include the full-time domain simulation model, average system frequency (ASF), and system frequency response (SFR) [10-16]. The full-time domain simulation model can simulate the dynamic equipment and network of the system in detail. However, it has a high dimensionality and a large amount of calculation [10,11]. Both ASF and SFR models assume that the system frequency remains the same and ignore the reactive power-voltage dynamic effects. They can intuitively reflect the relationship between active power balance and system frequency, and significantly reduce the amount of calculation $[12,13]$. However, the ignorance of the frequency control of wind power has made these models no longer suitable for the study of the dynamic frequency characteristics of the grid [14]. In this regard, Ghosh S et al. [15,16] considered the effects of wind power virtual inertial response and primary frequency regulation response. In [15], the inherent inertia time constant of wind power was added to the improved ASF model. However, the effect of the inertial response of DFIG is time-varying, which will bring a biased result if using an inherent constant to represent. Yan et al. [16] added the primary frequency-regulation droop control link of DFIG as a static model to the improved ASF model, which cannot fully reveal the dynamic response characteristics of the primary frequency regulation control of the DFIG.

\section{(2) Assessment method}

For the measurement of the wind power capacity that can be connected to the power system, most of the current research has used simulation methods to solve the problem [17-21]. Zhang J. et al. [17] conducted many dynamic simulation tests based on the initial value of wind generation penetration they set at the beginning. According to various constraints, such as voltage and frequency, and the deviation of multiple indicators in each simulation, the limit value of the penetration power was continuously revised until the set constraint conditions were met. Although the penetration power can be obtained accurately, this method does not provide an analytical calculation method. The process of this simulation-based method is relatively complicated, and it must be re-operated when the system operation mode changes, which will bring a certain computational burden. In [18], the optimization methods were adopted to solve the maximum wind generation penetration with transient stability as a constraint and the maximum acceptable wind power capacity in the system as the objective. However, it ignored a large number of physical quantities and the frequency-regulation control of the DFIG, so the accuracy needs to be improved. Wang Man et al. [19] presented a novel three-stage optimization framework that targets the estimation of wind penetration limit based on the chance-constrained OPF incorporated with transient stability constraints of the power system. The analysis of dynamic model requires time series data, e.g., forecasting values of generations and demands [20]. With the popularity of wind power participating in primary frequency regulation, Shichun L. [21] established a primary frequency-regulation control response model of the DFIG and the frequency response model of the power system. On this basis, the researchers took the steady-state frequency deviation of the system and the frequency change rate at the initial moment of the disturbance as constraints and proposed a method for calculating the maximum wind generation penetration. However, the use of a higher-order wind power primary frequency-regulation model dramatically increases the computational complexity.

The above review of the literature indicates that the calculation of limit wind generation penetration is an issue that has not as yet been studied in sufficient depth. The limitations of the existing research are mainly manifested in the following aspects. Firstly, some of the previous research focused on the dynamic modeling of wind generators and primary frequency support. How to dynamically display the inertial response process and the primary frequency modulation process of the DFIG with 
additional frequency control in the system frequency dynamic modeling without greatly increasing the amount of calculations requires further research. Moreover, in the evaluation method of the maximum wind generation penetration, it is necessary to improve the accuracy and applicability of the calculation method and reduce the calculation complexity while considering the frequency regulation control of DFIG.

\subsection{Proposed Method and Contributions}

In this study, an analytical solution method for the maximum wind generation penetration that considers the frequency-regulation control of DFIGs and frequency stability constraints is proposed. In this regard, the main contributions of this study can be summarized as follows:

(1) Contrarily to $[15,16]$ which simply use static models to characterize the frequency regulation characteristics of DFIG, this paper calculates the equivalent inertial time constant in the form of the transfer function and adds a dynamic primary frequency-regulation link to characterize the inertial response and the primary frequency regulation process of the DFIG. This improvement can fully demonstrate the control function of DFIG in the system frequency dynamic response.

(2) By considering the participation of the DFIG in frequency regulation, the frequency response model of the power system with wind power in the time scales of the inertial response process and the primary modulation is established. The frequency-domain analytical solution of the system frequency is obtained.

(3) Based on the obtained expression of system frequency, the maximum wind generation penetration can be analytically calculated under the dynamic and static frequency stability constraints. Compared with solving through repeated simulation operations [17], this method is suitable for various situations and can fully demonstrate the control process of the DFIG while reducing the computational complexity. Compared with the optimization algorithm that ignores a large number of dynamic processes [18], this calculation can completely mathematically model the frequency dynamic response characteristics of the system, to better understand the whole process of the system frequency dynamic response.

\subsection{Organization of the Paper}

This paper is organized as follows: the dynamic modeling of the inertial response process of DFIG is analyzed in Section 2, and the equivalent inertia time constant of the DFIG is calculated in Section 3. In Section 4, the SFR model formulations of the power system with wind power are established. The maximum wind generation penetration considering frequency stability constraint is analytically solved in Section 5. The time-domain and assessment simulation results are provided in Section 6. Finally, the paper is concluded in Section 7.

\section{Dynamic Modeling of Inertial Response Process of DFIG}

In order to solve the problem in a targeted manner, this section establishes a simplified DFIG model suitable for studying frequency response. Considering that the inertial response has the dynamic response characteristics of the electromechanical time scale, the following assumptions were made. Firstly, it is thought that wind speed and mechanical torque remain unchanged during the inertial response dynamic process. Secondly, when the wind speed is greater than the rated wind speed for a long time, the wind turbine does not use inertial control but changes the pitch angle to realize frequency regulation due to the constraints of mechanical structure and electrical load bearing capacity. This process involves a more complex modeling process, which needs to be further discussed in future research. Therefore, only a case where the wind speed is less than the rated wind speed is discussed here. Thirdly, the secondary frequency regulation of the DFIG was disabled due to the limitation of the structure of wind turbines. In the modeling of the DFIG, the secondary frequency regulation is not considered. According to the above assumptions, the models closely related to inertial 
response include the generator electromechanical transient model, frequency regulation controller model, speed controller model, and power tracking control model.

\subsection{Generator Electromechanical Transient Model}

The transient electromechanical characteristics of DFIG can be represented by an equivalent mathematical model in a two-phase $\mathrm{d}-\mathrm{q}$ rotating coordinate system. The flux equation of the generator can be expressed as

$$
\left\{\begin{array}{l}
\psi_{d s}=L_{s} i_{d s}+L_{m} i_{d r} \\
\psi_{q s}=L_{s} i_{\mathrm{qs}}+L_{m} i_{q r} \\
\psi_{d r}=L_{m} i_{d s}+L_{r} i_{d r} \\
\psi_{q r}=L_{m} i_{\mathrm{qs}}+L_{r} i_{r q}
\end{array}\right.
$$

where $\psi_{d s}, \psi_{q s}$ are the d-axis and q-axis component of the stator flux linkage. $\psi_{d r}, \psi_{q r}$ is the $d$-axis and $q$-axis component of the rotor flux linkage. $i_{d s}, i_{q s}$ are the $d$-axis and $q$-axis component of the stator current. $i_{d r}, i_{q r}$ are the d-axis and q-axis component of the rotor current. $L_{m}$ is the mutual inductance between the stator and rotor windings. $L_{s}, L_{r}$ is the self-inductance of the stator winding and the rotor winding. $\omega_{r}$ is the rotor speed.

Ignoring the influence of the shafting characteristics on the power grid characteristics, use $\left[\psi_{d s}, \psi_{q s}\right.$, $\left.i_{d r}, i_{q r}, \omega_{r}\right]$ as the state variables to establish a fifth-order transient model to show the electromagnetic torque $T_{\mathrm{em}}$ directly related to the virtual inertial response:

$$
T_{\mathrm{em}}=\frac{3 p L_{\mathrm{m}}}{4 L_{s}}\left(\psi_{d s} i_{q r}-\psi_{q s} i_{d r}\right)
$$

where $p$ is the number of generator pole pairs.

In a synchronous rotating coordinate system based on stator voltage vector control, $\psi_{q s}=0$. Therefore, the expression of electromagnetic torque can be simplified to

$$
T_{\mathrm{em}}=\frac{3 p L_{\mathrm{m}}}{4 L_{s}} \psi_{d s} i_{q r}=k_{1} \psi_{d s} i_{q r}
$$

where $k_{1}$ is the constant coefficient of $T_{e m}$.

At the same time, the rotor motion equation of the generator is

$$
2 H_{D F I G} \frac{d \omega_{\mathrm{r}}}{d t}=T_{\text {mach }}-T_{\mathrm{e}}
$$

where $H_{D F I G}$ is the inherent inertia time constant of the DFIG. $T_{\text {mach }}$ is the mechanical torque of the generator.

\subsection{Speed Controller Model}

In steady state, DFIG realizes real-time speed tracking through the speed controller. When the speed of the DFIG changes, the inertial response process will be dynamically adjusted with the speed controller. The mathematical model describing the dynamic response process of the speed controller is

$$
\Delta T_{v c}^{*}=\left(K_{p v}+\frac{K_{i v}}{s}\right)\left(\omega_{\mathrm{r}}-\omega_{r e f}\right)=\left(K_{p v}+\frac{K_{i v}}{s}\right) \Delta \omega_{\mathrm{r}}
$$

where $\Delta T_{v c}^{*}$ is the output reference torque increment of the speed controller. $K_{i v}$ is the integral coefficient. $K_{p v}$ is the proportional coefficient. $\Delta \omega_{\mathrm{r}}$ is the rate of change of the rotor speed of the DFIG. 


\subsection{Power Tracking Controller Model}

The energy conversion efficiency of a variable speed wind turbine is determined by the wind energy utilization factor. When the DFIG is running in the maximum power tracking state in the initial state, the rotational speed usually tracks the wind speed to maintain the best tip speed ratio $\lambda_{\text {opt }}$. At this time, the DFIG is running at the highest efficiency point, and the wind energy utilization coefficient takes the maximum value. In order to participate in power system frequency regulation, DFIGs need to reserve spare capacity in advance. For this purpose, overspeed control is usually selected to obtain spare capacity. At this time, the DFIG gives up capturing the maximum power and operates with deloaded power curves, which are pre-defined according to the requested active power output imposed by wind park supervisory control. The output power torque $T^{*}$ del under this condition is [22]

$$
T_{d e l}^{*}=k_{d e l} \omega_{\mathrm{r}}^{3}
$$

where $k_{d e l}$ is the derating power tracking coefficient of DFIG.

When the wind speed is constant, and the system has a small disturbance, the electromagnetic torque increment $\Delta T^{*}$ del provided by the power tracking controller is

$$
\Delta T_{d e l}^{*}=3 k_{d e l} \omega_{\mathrm{r} 0}^{2} \Delta \omega_{\mathrm{r}}
$$

where $\omega_{\mathrm{r} 0}$ is the initial value of the rotor angular velocity of DFIG.

\subsection{SFPD Controller Model}

The existing DFIG mostly adopts the supplementary frequency proportion-differentiation (SFPD) frequency regulation control that combines droop control and virtual inertia control. The virtual inertia control adds an additional electromagnetic torque proportional to the change rate of the system frequency, which enables the DFIG to spontaneously realize the negative feedback effect of frequency change and release the kinetic energy stored in the generator rotor during the dynamic process. Therefore, the DFIG can quickly realize the virtual inertial response within a short period of time when the disturbance occurs. The droop control is the mainstream method for primary regulation, which takes the real-time frequency deviation $\Delta f$ of the system as the feedback quantity and adds an active power control signal through the proportional gain link to adjust the active output. Compared with virtual inertial control, this method mainly works on a longer time scale after the disturbance. It effectively increases the output active power of the wind turbine and restores the system frequency.

The reference value of additional electromagnetic torque $\Delta T^{*}$ emu generated by frequency regulation control is

$$
\Delta T_{\mathrm{emu}}^{*}=-\frac{K_{i f}}{T s+1} s \Delta \omega_{s}-K_{d f} \Delta \omega_{s}
$$

where $\Delta T^{*}$ emu is the output reference torque increment of the SFPD frequency regulation controller. $K_{i f}$ is the proportional coefficient of the virtual inertia control link. $K_{d f}$ is the proportional coefficient of the droop control link. $T$ is the time constant of the low-pass filter. $\Delta \omega_{s}$ is the increment of the synchronous angular velocity of the system.

As shown in Figure 1, by establishing the control model of each module, a simplified control model of the DFIG can be obtained. Moreover, $T_{\max }$ and $T_{\min }$ are the maximum and minimum reference torques that the speed controller can output. $f_{S}$ is the frequency of the power system [23]. 


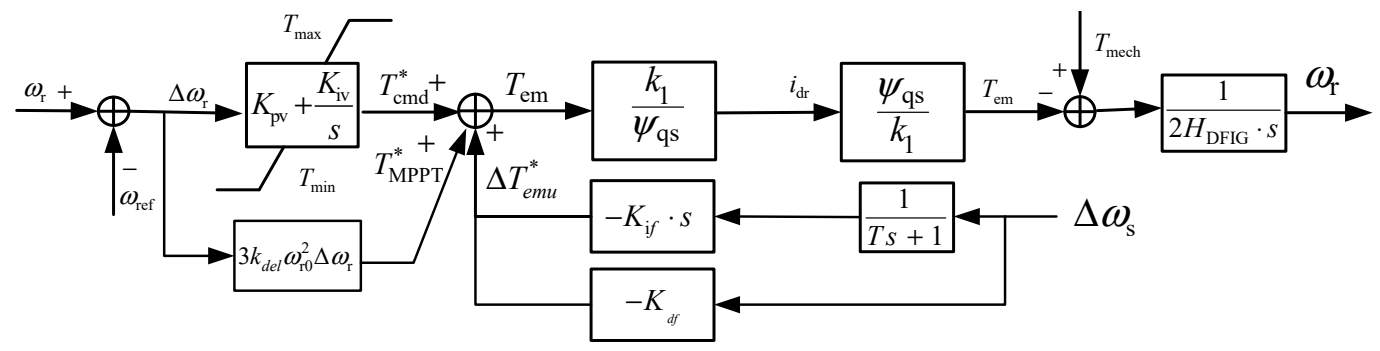

Figure 1. The control model of the doubly fed induction generator.

\section{Calculation of Equivalent Inertia Time Constant of DFIG}

When DFIG adds SFPD frequency regulation control so that it can provide certain inertial support, the rotor speed of the DFIG is no longer decoupled from the angular velocity of the system. At this time, DFIG can support the system frequency by increasing active output according to frequency change when the system is disturbed. Furthermore, the supporting capacity can be characterized by the defined equivalent inertia time constant. Its value reflects the virtual inertia response capability of the wind turbine relative to the grid frequency change.

According to [23], the variation of kinetic energy during the inertial response of DFIG is expressed by the deviation of rotor speed and inherent inertial torque and the variation of system synchronous angular velocity and the virtual moment of inertia of DFIG. Thus, an equation relationship between them can be established. The virtual moment of inertia of the DFIG can be obtained as

$$
J_{e q u}=\frac{\left(2 \omega_{r 0}+\Delta \omega_{r}\right) \Delta \omega_{r}}{\left(2 \omega_{s 0}+\Delta \omega_{s}\right) \Delta \omega_{s}} J_{D F I G} \approx \frac{\Delta \omega_{r} \omega_{r}}{\Delta \omega_{s} \omega_{s}} J_{D F I G}
$$

where $J_{\text {equ }}$ is the virtual moment of inertia of the DFIG. $\omega_{\mathrm{s} 0}$ is the initial synchronous angular velocity of the system. $J_{D F I G}$ is the inherent moment of inertia of the DFIG.

According to Equation (9) and the definition of inertia time constant, the virtual inertia time constant of the DFIG in the inertial response process can be defined as [23]

$$
H_{e q D F I G}=\frac{J_{e q u} \omega_{s 0}^{2}}{2 p^{2} S_{N}}=\frac{J_{\text {equ }} \omega_{\text {nom }}^{2} \frac{\omega_{s 0}^{2}}{\omega_{\text {nom }}^{2}}}{2 p^{2} S_{N}}=\frac{\Delta \omega_{r}}{\Delta \omega_{s}}\left(\frac{\omega_{s 0} \omega_{r 0}}{\omega_{\text {nom }}^{2}}\right) H_{D F I G}
$$

where $\omega_{\text {nom }}$ is the rated angular velocity of the DFIG. $\mathrm{S}_{\mathrm{N}}$ is the rated capacity of the DFIG. $H_{\text {eqDFIG }}$ quantitatively characterizes the inertial response capability of the DFIG when the system frequency fluctuates, and its size is determined by $\Delta \omega_{r} / \Delta \omega_{s}$.

At the same time, the DFIG mainly realizes the inertial response process by changing the electromagnetic torque, so $H_{e q D F I}$ is mainly related to the electromagnetic torque increase. Because the SFPD-integrated frequency regulation controller, power tracking controller, and speed controller jointly affect the inertial response process of DFIG, the total electromagnetic torque $\Delta T_{\mathrm{em}}$ can be expressed as the sum of their output torque increments. By combining Equations (5)-(8), we obtain

$$
\Delta T_{\mathrm{em}}=\left(K_{p v}+\frac{K_{i v}}{s}\right) \Delta \omega_{r}+3 k_{d e l} \omega_{\mathrm{r} 0}^{2} \Delta \omega_{\mathrm{r}}-\left(\frac{K_{i f} s}{T s+1} \Delta \omega_{s}+K_{d f} \Delta \omega_{s}\right)
$$

At the same time, by considering the inertial response process of a smaller time scale and ignoring the change in the rotor speed of the DFIG, the frequency-domain expression obtained from the rotor motion equation can be obtained from (4)

$$
2 H_{D F I G} \cdot \Delta \omega_{r} s=-\Delta T_{\mathrm{em}}
$$


Bringing in Equation (19), we obtain

$$
\frac{\Delta \omega_{r}}{\Delta \omega_{s}}=\frac{\left(K_{i f} s+K_{d f}(T s+1)\right)}{(T s+1)\left(2 H_{D F I G} \omega_{\mathrm{r}} \cdot s+\left(K_{p v}+\frac{K_{i v}}{s}\right)+3 k_{d e l} \omega_{\mathrm{r} 0}^{2}\right)}
$$

Combined with Equation (10), the frequency-domain expression of $H_{e q D F I G}$ can be obtained as

$$
H_{e q D F I G}=\frac{H_{D F I G} \omega_{\mathrm{s} 0} \omega_{\mathrm{r} 0} \cdot\left(K_{i f} s+K_{d f}(T s+1)\right)}{\omega_{\text {norm }}^{2}(T s+1)\left(2 H_{D F I G} \omega_{\mathrm{r} 0} \cdot s+\left(K_{p v}+\frac{K_{i v}}{s}\right)+3 k_{d e l} \omega_{\mathrm{r} 0}^{2}\right)}
$$

\section{Power System Frequency Response Model}

\subsection{Frequency Response Model of Power System without Wind Power}

When a transient disturbance occurs in the system, the frequency is dynamically adjusted and restored to a steady-state value under the regulation of synchronous unit and load. The system frequency response process has a relatively long time scale. In order to facilitate calculation, the links with a smaller time scale can be ignored, and the system model can be appropriately simplified. In [24-26], a simplified second-order frequency response model is proposed. The system frequency response process only considers the generator rotor and steam turbine reheater with a large inertia time constant [24], as shown in Figure 2. The model assumes that the synchronous generators are all driven by reheat turbines, and all conventional generators in the system are equivalent to one turbine generator. $H$ is the equivalent inertia time constant of synchronous generator set after equivalent calculation. $R$ is the droop coefficient of the governor. $T R$ is the time constant of the turbine reheater. $F H$ is the proportion of the output power of the high-pressure boiler. $K_{m}$ is the mechanical power gain factor. $\Delta P_{G}$ is the change in the mechanical power of the generator. $\Delta P a$ is the acceleration power assumed by the rotor. $\Delta P_{d}$ is the disturbance power. $D$ is the load-damping coefficient.

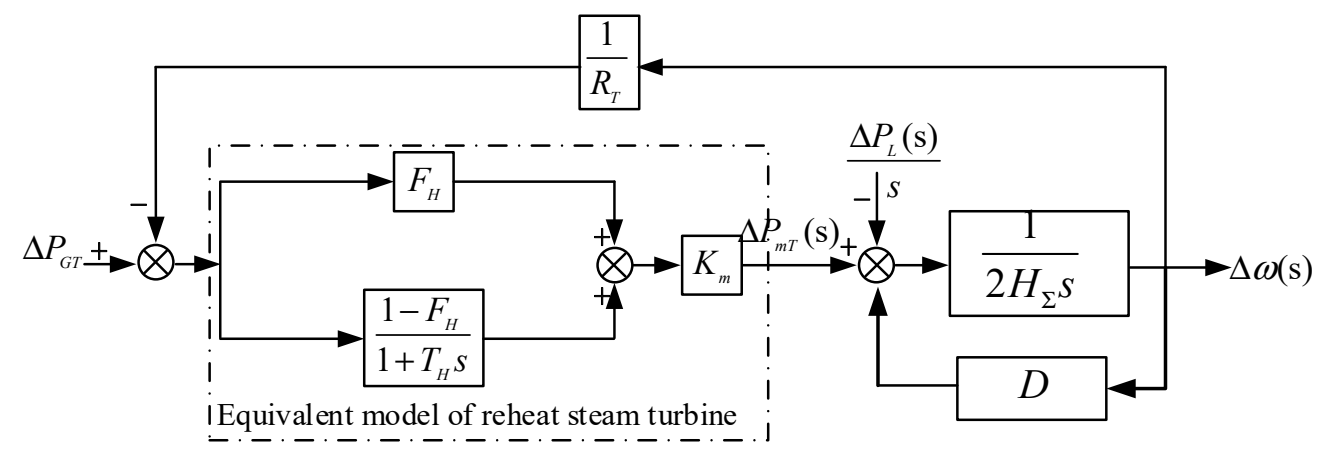

Figure 2. Frequency response model of the power system containing only synchronous generators.

According to the model in Figure 2, the equation of the system frequency response can be listed as

$$
\left\{\begin{array}{l}
2 H \frac{d \Delta \omega}{d t}=\Delta P_{d}-\Delta P_{G}-D \Delta \omega \\
\Delta P_{G}=G_{s}(s) \Delta \omega \\
G_{s}(s)=\frac{K_{m}\left(1+F_{H} T_{R} s\right)}{R\left(1+T_{R} s\right)}
\end{array}\right.
$$

where $G_{s}(s)$ is the simplified primary frequency regulation transfer function model of conventional thermal power units. $\Delta \omega$ is the system frequency deviation per unit value. Its meaning is consistent with the above $\Delta \omega_{s}$. 
Usually, a step function is used to describe the instantaneous power disturbance of the system as such:

$$
\Delta P_{\mathrm{d}}(s)=\frac{\Delta P_{\mathrm{L}}}{s S_{\mathrm{B}}}
$$

where $\Delta P_{\text {step }}$ is the disturbance magnitude in per unit. We assume that all equations are on a common system base $S_{\mathrm{B}}$, which is equal to the sum of the ratings of all generating units in the system. $\Delta P_{\mathrm{L}}$ is the actual size of the disturbance power.

By applying the model shown in Figure 2 to a power system with $\mathrm{n}$ synchronous generators, the inertia time constant of the equivalent machine and the droop coefficient of the governor in the model can be expressed as

$$
H=\frac{\sum_{i=1}^{n} S_{i} H_{i}}{\sum_{i=1}^{n} S_{i}}, \frac{1}{R}=\frac{\sum_{i=1}^{n} S_{i} \frac{1}{R_{i}}}{\sum_{i=1}^{n} S_{i}}
$$

where $S_{i}, H_{i}$ and $R_{i}$ are, respectively, the rated capacity, inertia time constant and droop coefficient of the $i$-th synchronous machine.

\subsection{Frequency Response Model of Power System with Wind Power}

Considering that wind power is connected to the power system, wind power and synchronous generator sets balance the load power together. The grid conditions are basically the same. The system can be set to contain $n$ synchronous generators and $m$ wind turbines. Define the wind generation penetration in the power system $\alpha$ as the ratio of grid-connected wind power capacity to the total installed capacity of the system. That is,

$$
\alpha=\frac{\sum_{j=1}^{m} S_{j}}{\sum_{i=1}^{n} S_{i}+\sum_{j=1}^{m} S_{j}}
$$

where $\alpha$ is the wind generation penetration. $S_{j}$ is the rated capacity of the $j$-th wind turbine. $n^{\prime}$ and $m$ are the number of synchronous machines and wind turbines, respectively.

At this time, the inertia time constant of the equivalence machine in the model and the droop coefficient of governor in Figure 2 can be expressed as

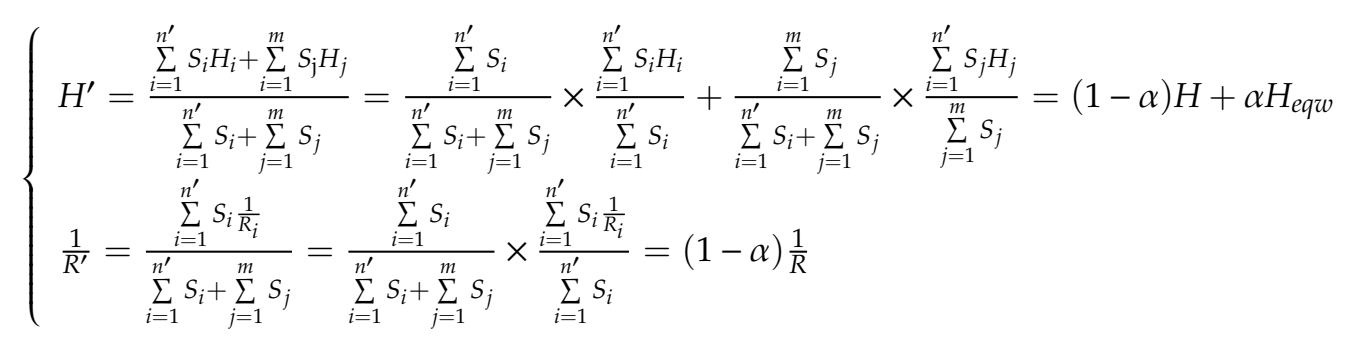

where $H^{\prime}$ and $R^{\prime}$ are the inertia time constant of the equivalence machine, and the droop coefficient of the governor after the wind turbines participating in the frequency control are connected to the power system. It can be seen that the wind turbines participating in frequency control are connected to the system, which will change the equivalent inertia time constant of the system and the droop coefficient of the governor.

When DFIG adopts the SFPD frequency regulation control method, the droop control link will affect the primary frequency regulation process of the system on a longer time scale. At this time, the change of speed cannot be ignored, and it is necessary to consider the dynamic process to be larger than part of the inertial response time scale. Therefore, when considering the dynamic modeling of the 
power system, it is necessary to establish a dynamic model of the primary frequency regulation of the DFIG. This model describes the dynamic process in which the unit adjusts the output mechanical power to suppress the frequency disturbance when the power system frequency is disturbed. It can be obtained by solving the transfer function of unit output power increment and system frequency deviation.

When the DFIG adopts the integrated controller to participate in the system frequency adjustment, a certain reserve capacity needs to be reserved. When the DFIG participates in frequency regulation by obtaining reserve capacity through overspeed control, the decrease in rotor speed during frequency regulation causes the operating point of the deloaded power curve to move downward. Part of the active power increment is used to provide steady-state power support for the system. The other part needs to be used to compensate for the power loss caused by the downward movement of the deloaded operating point in the load-shedding power tracking curve. Therefore, during the frequency disturbance accident, the electromagnetic power change of the DFIG $\Delta P_{e}$ can be expressed as

$$
\Delta P_{e}=3 k_{\mathrm{del}} \omega_{\mathrm{r} 0}^{2} \Delta \omega_{\mathrm{r}}+K_{\mathrm{d} f} \Delta \omega+\frac{K_{i f} \mathcal{S}}{T s+1} \Delta \omega
$$

where $3 k_{\mathrm{del}} \omega_{\mathrm{r} 0}{ }^{2} \Delta \omega_{\mathrm{r}}^{2}$ is equivalent to the mechanical power loss caused by the lowering of the deloaded operating point during the frequency adjustment of the DFIG.

At the same time, the mechanical power $P_{\mathrm{m}}$ captured under deloaded operation of the DFIG can be expressed as

$$
P_{\mathrm{m}}=\frac{1}{2} \rho S C_{\mathrm{P}}^{\prime} v^{3}
$$

where $\rho$ is the air density. $S$ is the area swept by the blade of the DFIG. $v$ is the wind speed. $C^{\prime} p$ is the wind energy utilization coefficient under deloaded operation of the DFIG.

Assuming that the wind speed remains constant during the primary frequency regulation response, the wind speed can be set as the initial steady-state wind speed $v_{0}$. Then, $P_{m}$ is uniquely determined by $C^{\prime}{ }_{p}$. There is a strong nonlinear implicit function relationship between $C^{\prime} p$ and blade tip speed ratio $\lambda$ and pitch angle $\beta$. In order to simplify the order in the actual modeling calculation, the wind energy utilization coefficient $C^{\prime}{ }_{p}$ is simplified to an explicit functional relationship between $\lambda$ and $\beta$ [27]. It is assumed that the blade response is not decoupled from any significant participation in the torsional dynamics. Without individual representation of the two blades, there is no need to include wind shear and tower shadow effects at a detailed level. The wind models which are available include an additive term representing the net effect of rotational non-linearities in the driving torque:

$$
C_{p}^{\prime}=(1-d \%)\left[(0.44-0.0167 \beta) \sin \left[\frac{\pi(\lambda-3)}{15-0.3 \beta}\right]-0.00184(\lambda-3) \beta\right]
$$

where the tip speed ratio $\lambda \omega R / v$. $\omega$ is the rotation speed of the wind wheel. $R$ is the radius of the wind wheel. $d \%$ is the load reduction ratio. Assume that the wind speed $v$ remains constant during a frequency modulation response. The value of the wind energy utilization coefficient $C^{\prime}{ }_{p}$ is only determined by $\omega$ and $\beta$ in a short time. Then, we can obtain the small-signal incremental of $C_{p}(\lambda, \beta)$ that can be expressed in $\omega_{r}$ and $\beta$ :

$$
\Delta C_{p}^{\prime}(\lambda, \beta)=\Delta C_{p}^{\prime}\left(\omega_{\mathrm{r}}, \beta\right)=\frac{\partial C_{P}}{\partial \omega_{\mathrm{r}}} \Delta \omega_{\mathrm{r}}+\frac{\partial C_{P}}{\partial \omega_{\mathrm{r}}} \beta=\left(\mathrm{y}_{0}+\mathrm{y}_{1}\right) \Delta \omega_{\mathrm{r}}+\left(\mathrm{y}_{2}+\mathrm{y}_{3}+\mathrm{y}_{4}\right) \beta
$$

where

$$
\begin{aligned}
& y_{0}=\frac{\pi R\left(0.44-0.0167 \beta_{0}\right)}{v_{w 0}\left(15-0.3 \beta_{0}\right)} \cos \left[\frac{\pi R \omega_{\mathrm{r} 0} / v_{w 0}-3 \pi}{\left(15-0.3 \beta_{0}\right)}\right] ; y_{1}=-0.0018\left(R \beta_{0} / v_{w 0}\right)(1-d \%) ; \\
& y_{2}=-0.0167 \sin \left[\frac{\pi R \omega_{\mathrm{r} 0} / v_{w 0}-3 \pi}{\left(15-0.3 \beta_{0}\right)}\right](1-d \%) ; \\
& y_{3}=\left(0.44-0.0167 \beta_{0}\right) \cos \left[\frac{3 \pi^{2}\left(R \omega_{\mathrm{r} 0} / v_{w 0}-3\right)^{2}}{\left(15-0.3 \beta_{0}\right)^{3}}\right](1-d \%) \\
& y_{4}=-0.00184\left(R \omega_{\mathrm{r} 0} / v_{w 0}-3\right)(1-d \%)
\end{aligned}
$$


When using the speed control method, if the wind speed is less than the rated wind speed, the pitch angle will not act. Considering $\beta$, we obtain

$$
\Delta C_{p}^{\prime}(\lambda, \beta)=\Delta C_{p}^{\prime}\left(\omega_{\mathrm{r}}, \beta=0\right)=(1-d \%) \frac{0.29 \pi}{\mathrm{v}_{w 0}} \cos \left(\frac{\pi R \omega_{\mathrm{r} 0}}{15}-\frac{\pi}{5}\right) \Delta \omega_{\mathrm{r}}
$$

Therefore, the wind energy utilization coefficient function $\Delta C^{\prime} p$ can be expressed as a linear function of $\Delta \omega_{\mathrm{r}}$ under deloaded operation of the DFIG in the simplified calculation:

$$
\Delta P_{\mathrm{m}}=\frac{1}{2} \rho S v^{3} \Delta C_{p}^{\prime}=\frac{1}{2} \rho S v^{3} \frac{\partial C_{p}^{\prime}}{\partial \omega_{\mathrm{r}}} \Delta \omega_{\mathrm{r}}
$$

where $\left(\partial C_{p}^{\prime} / \partial \omega_{r}\right) \Delta \omega_{r}$ is the partial lead of the wind energy utilization coefficient function to the speed under deloaded operation of the DFIG. $\partial C_{p}^{\prime} / \partial \omega_{r}$ is the coefficient of the partial derivative. When the pitch angle is 0 , its value is $0.29 \pi(1-\mathrm{d} \%) \cos \left(\pi \mathrm{R} \omega_{\mathrm{r} 0} / 15 v_{w 0}-0.2 \pi\right)$.

When the wind speed remains constant and the pitch angle is fixed, the rotational speed affects the wind energy utilization coefficient function, which in turn affects the mechanical power change $\Delta P_{\mathrm{m}}$ captured by the DFIG.

In the primary frequency regulation stage, the change in mechanical torque cannot be ignored due to the large change in speed. Similarly, combining the small-signal analysis method and the rotor motion equation of the DFIG, we obtain

$$
2 H_{D F I G} \omega_{\mathrm{r} 0} s \Delta \omega_{\mathrm{r}}=\Delta P_{\mathrm{m}}-\Delta P_{\mathrm{e}}
$$

By incorporating Equations (18) and (24) into Equation (25) and eliminating the intermediate variable $\Delta \omega_{r}$, the frequency regulation response model of the DFIG can be obtained as follows:

$$
\Delta P_{\mathrm{e}}=\frac{2 H_{D F I G} \omega_{\mathrm{r} 0} S-\frac{1}{2} \rho S v^{3} \frac{\partial \Delta C_{p}^{\prime}}{\partial \omega_{\mathrm{r}}}}{2 H_{D F I G} \omega_{\mathrm{r} 0} S-\frac{1}{2} \rho S v^{3} \frac{\partial \Delta C_{p}^{\prime}}{\partial \omega_{\mathrm{r}}}-3 k_{\mathrm{del}} \omega_{\mathrm{r} 0}^{2}}\left(\frac{K_{i f} S}{T s+1}+K_{d f}\right) \Delta \omega
$$

Substituting the parameters of Equation (30) into Figure 2, the modified power system frequency response model, after the wind turbines participating in the frequency regulation control are connected, can be obtained, as shown in Figure 3.

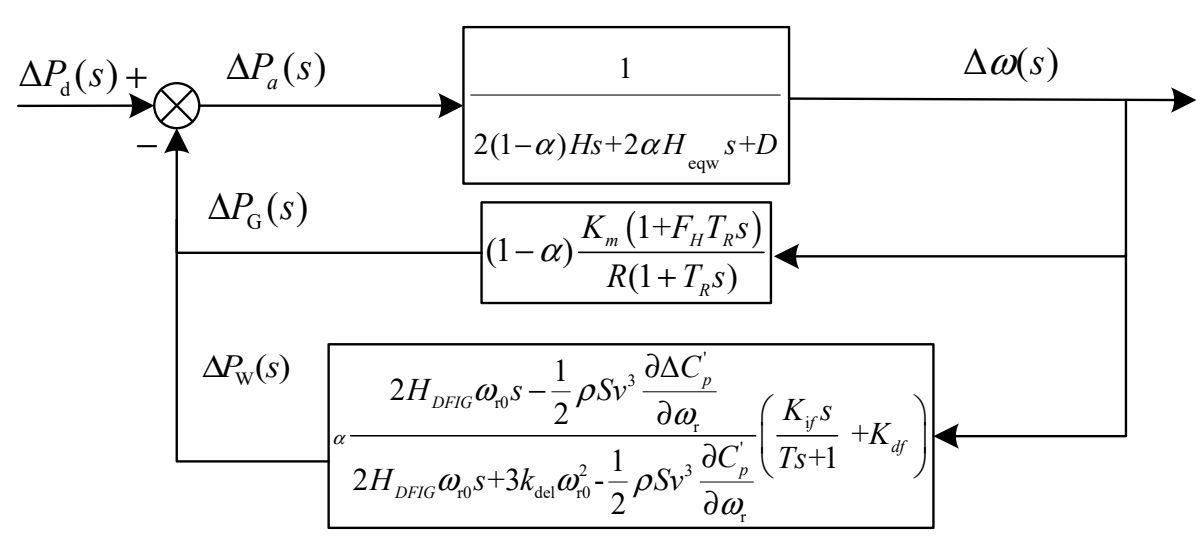

Figure 3. Frequency response model of power system connected with DFIG with SFPD frequency regulation control. 
According to Figure 3, it can be given that

$$
\left\{\begin{array}{l}
2\left((1-\alpha) H+\alpha H_{e q w}\right) \frac{d \Delta \omega}{d t}=\Delta P_{d}-\Delta P_{G}-\Delta P_{w}-D \Delta \omega \\
\Delta P_{w}=\alpha \frac{2 H_{D F I G} \omega_{\mathrm{r} 0} s-\frac{1}{2} \rho S v^{3} \frac{\partial C_{p}^{\prime}}{\partial \omega_{\mathrm{r}}}}{2 H_{D F I G} \omega_{\mathrm{r} 0} s+3 k_{\mathrm{del}} \omega_{\mathrm{r} 0}^{2}-\frac{1}{2} \rho S v^{3} \frac{C_{p}^{\prime}}{\partial \omega_{\mathrm{r}}}}\left(\frac{K_{i f} s}{T s+1}+K_{d f}\right) \Delta \omega \\
\Delta P_{G}=(1-\alpha) \frac{K_{m}\left(1+F_{H} T_{R} s\right)}{R\left(1+T_{R} s\right)} \Delta \omega
\end{array}\right.
$$

Therefore, the frequency-domain expression of the deviation per unit value of frequency is

$$
\Delta \omega(s)=\frac{\Delta P_{\mathrm{d}}(s)}{\left[2(1-\alpha) H s+2 \alpha H_{e q \mathrm{~W}} s+D\right]+(1-\alpha) K_{m} \frac{1+F_{H} T_{R} s}{R\left(1+T_{R} s\right)}+\alpha \frac{2 H_{D F I G} \omega_{\mathrm{r} 0} s-\frac{1}{2} \rho S v^{3} \frac{\partial S C_{p}^{\prime}}{\partial \omega_{\mathrm{r}}}}{2 H_{D F I G} \omega_{\mathrm{r} 0} s-\frac{1}{2} \rho S v^{3} \frac{\partial C_{p}^{\prime}}{\partial \omega_{\mathrm{r}}}+3 k_{\mathrm{del}} \omega_{\mathrm{r}}^{2}}\left(\frac{K_{\mathrm{i}} s}{T s+1}+K_{d f}\right)}
$$

\section{Maximum Penetration of DFIG Considering Frequency Stability Constraint}

\subsection{Maximum Penetration of DFIG Constrained by Steady-State Frequency Deviation}

The steady-state frequency deviation (SFD) can reflect the ability of the system to resist active disturbances through frequency regulation. If the SFD is large, it will not only affect the power quality but also increase the risk of system frequency instability when faced with large active power disturbances. Therefore, the power system usually stipulates that the SFD should be within $\pm 0.2 \mathrm{~Hz}$. According to the final value theorem of Laplace transform, the SFD of (28) can be obtained as

$$
\mathrm{SFD}=f_{\mathrm{N}_{t \rightarrow+\infty}} \lim _{t \rightarrow} \Delta \omega(t)=f_{\mathrm{N}} \lim _{s \rightarrow 0^{+}} s \Delta \omega(s)=\frac{f_{\mathrm{N}} \Delta P_{\mathrm{L}}}{S_{\mathrm{B}}\left(D+(1-\alpha) \frac{K_{m}}{R}+\alpha \frac{\frac{1}{2} \rho S v^{3} \frac{\partial \Delta C_{p}^{\prime}}{\partial \omega_{\mathrm{r}}}}{\frac{1}{2} \rho S v^{3} \frac{\partial C_{p}^{\prime}}{\partial \omega_{\mathrm{r}}}-3 k_{\mathrm{del}} \omega_{\mathrm{r} 0}^{2}} K_{d f}\right)}
$$

where $f_{\mathrm{N}}$ is the rated frequency of the system.

Assuming that the boundary of the steady-state frequency deviation of the system is $\xi$, the SFD satisfies

$$
\mathrm{SFD} \leq|\xi|
$$

By combining (29) and (30), the maximum penetration of DFIG under the frequency stability constraint can be obtained:

$$
\alpha_{\max 1}=\frac{\left(D+\frac{K_{m}}{R}-\frac{f_{\mathrm{N}} \Delta P_{\mathrm{L}}}{S_{\mathrm{B}}|\xi|}\right)\left(\frac{1}{2} \rho S v^{3} \frac{\partial \Delta C_{p}^{\prime}}{\partial \omega_{\mathrm{r}}}-3 k_{\mathrm{del}} \omega_{\mathrm{r} 0 \_\mathrm{del}}^{2}\right)}{\frac{K_{m}}{R}\left(\frac{1}{2} \rho S v^{3} \frac{\partial \Delta C_{p}^{\prime}}{\partial \omega_{\mathrm{r}}}-3 k_{\mathrm{del}} \omega_{\mathrm{r} 0 \_\mathrm{del}}^{2}\right)-\frac{1}{2} \rho S v^{3} \frac{\partial \Delta C_{p}^{\prime}}{\partial \omega_{\mathrm{r}}} K_{d f}}
$$

where $\alpha_{\max 1}$ is the maximum wind generation penetration of the wind power under the constraint of steady-state frequency deviation.

It can be seen that the maximum wind generation penetration is mainly affected by factors such as the droop control coefficient $K_{d f}$ of the DFIG, the load change level $\Delta P_{\mathrm{L}} / S_{\mathrm{B}}$, and the load reduction ratio of DFIG when constrained by the steady-state frequency deviation. The load reduction ratio of DFIG mainly affects the partial conduction of mechanical power to speed in the load reduction condition. The droop control coefficient $K_{d f}$ has a more significant influence on the steady-state frequency deviation, and the virtual inertia control coefficient has a small impact on the steady-state frequency deviation. 


\subsection{Maximum Penetration of DFIG Constrained by Dynamic Rate of Change of Frequency}

The rate of change of frequency (ROCOF) reflects the speed of frequency change of the power system when the system is disturbed. The frequency change rate is an important indicator of the dynamic frequency response of the system, which is directly related to whether the system frequency reaches the dynamic safety limit. The starting fixed value of the load shedding action of the existing frequency change rate relay is usually set at $\pm 0.05 \mathrm{~Hz} / \mathrm{s} \sim 0.1 \mathrm{~Hz} / \mathrm{s}$. Therefore, the boundary value of the frequency change rate is $\eta= \pm 0.05 \mathrm{~Hz} / \mathrm{s}$ in the calculation of this article. Usually, the frequency change rate reaches its maximum value at the beginning of the frequency disturbance caused by power change. According to the Laplace initial value theorem, the maximum value of the frequency change rate can be obtained as follows:

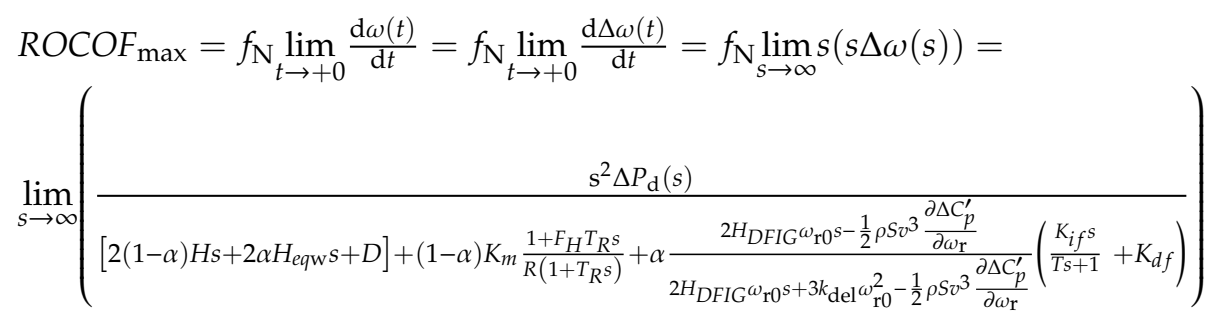

Assuming that the boundary of the system frequency change rate is $\eta$, ROCOF satisfies

$$
\text { ROCOF } \leq|\eta|
$$

By combining (32) and (33), it can be obtained that the maximum wind generation penetration under the constraint of dynamic frequency stability satisfies

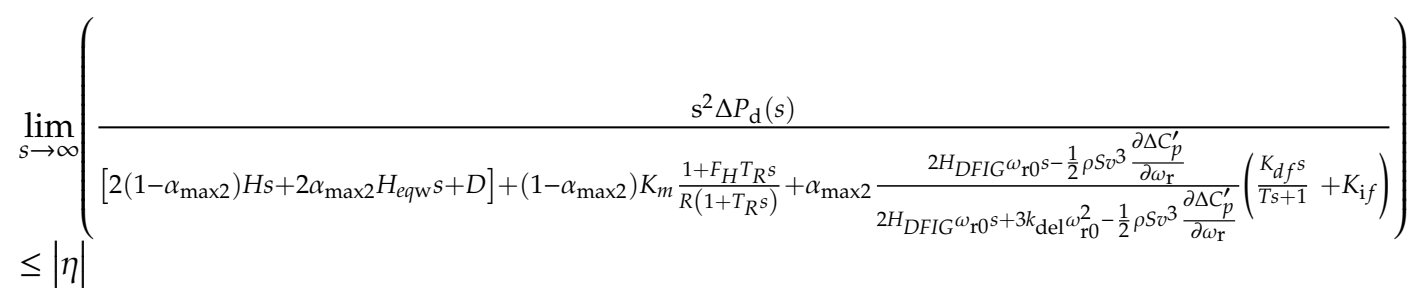

It can be seen that the maximum wind generation penetration has more influence factors when the dynamic frequency change rate is constrained. It mainly includes the droop control coefficient $K_{d f}$, the proportional coefficient $K_{i f}$ of the virtual inertia control link, the load change level $\Delta P_{L} / S_{B}$, and the load reduction ratio of the DFIG. The proportional coefficient $K_{i f}$ of the virtual inertia control link has a significant influence on the result.

Considering the above two situations and taking the smaller value, the maximum wind generation penetration can be obtained as follows:

$$
\alpha_{\max }=\min \left(\alpha_{\max 1}, \alpha_{\max 2}\right)
$$

\section{Case Study}

This paper builds the model shown in Figure 4 on the MATLAB/Simulink simulation platform. This model is based on the detailed nonlinear simulation model of the Simulink module and is used to verify the accuracy of Equation (31). The model is based on the IEEE 9-node model. The three synchronous generators are all thermal power units that are equivalent to several units and are merged into the wind farm on bus 9. Its initial base capacity is $100 \mathrm{MVA}$, and then it changes with simulation conditions. The wind farm is composed of several DFIGs. The power system frequency response model parameters are shown in Table 1, and the parameters of DFIG are shown in Table 2. The number 
of DFIG in the wind farm is determined according to the simulation scenario. Assuming that the wind speed is constant at $9 \mathrm{~m} / \mathrm{s}$ within the time scale of the first frequency regulation response after the disturbance, the active power balance is maintained. The remaining parameters of the system are shown in [28].

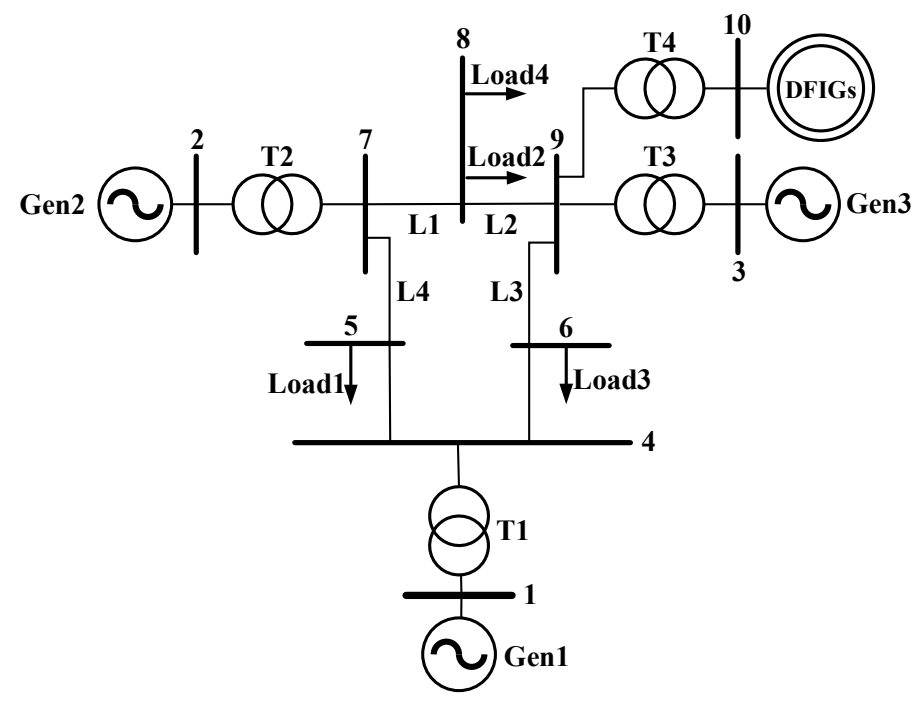

Figure 4. Diagram of the simulation system.

Table 1. IEEE ${ }^{1} 9$ node system network node parameters.

\begin{tabular}{ccc}
\hline Classification & Parameter & Value \\
\hline & Rated voltage $V_{n}$ & $18 \mathrm{kV}$ \\
& Rated power $P_{n}$ & $100 \mathrm{MW}$ \\
Synchronous generator & Stator resistance $R_{S}$ & $0.00285 \mathrm{pu}$ \\
& Straight shaft synchronous reactance $X_{\mathrm{d}}$ & $0.896 \mathrm{pu}$ \\
& Straight axis transient synchronous reactance $X^{\prime}{ }_{\mathrm{d}}$ & $0.12 \mathrm{pu}$ \\
& Direct-axis sub-transient synchronous reactance $X^{\prime \prime}{ }_{\mathrm{d}}$ & $0.12 \mathrm{pu}$ \\
Quadrature axis synchronous reactance $X_{\mathrm{q}}$ & $0.896 \mathrm{pu}$ \\
& Quadrature axis sub-transient synchronous reactance $X^{\prime \prime}{ }_{\mathrm{q}}$ & $0.12 \mathrm{pu}$ \\
& Inertial time constant $\mathrm{H}$ & $6.4 \mathrm{~s}$ \\
& Damping coefficient $\mathrm{D}$ & 0 \\
\hline Transformer & Rated voltage $V_{n 1}: V_{n 2}$ & $18 \mathrm{kV}: 220 \mathrm{kV}$ \\
& Rated capacity $S_{n}$ & $100 \mathrm{MVA}$ \\
& Equivalent resistance $R_{T}$ & $0.002 \mathrm{pu}$ \\
& Equivalent inductance $L_{T}$ & $0.0625 \mathrm{pu}$ \\
& Magnetizing inductance $L_{m T}$ & $10 \mathrm{pu}$ \\
\hline
\end{tabular}

${ }^{1}$ Institute of Electrical and Electronics Engineers.

Table 2. Parameters of 1.5MW DFIG.

\begin{tabular}{cccccccccc}
\hline$V \boldsymbol{n}[\mathrm{V}]$ & $\boldsymbol{P}_{\mathrm{n}}[\mathrm{MW}]$ & $\omega_{\text {nom }}[\mathrm{rad} / \mathrm{s}]$ & $\mathrm{T}[\mathrm{s}]$ & $\boldsymbol{R}_{\mathrm{s}}$ [p.u] & $\boldsymbol{L}_{\mathrm{s}}$ [p.u.] & $\boldsymbol{R}_{\mathrm{r}}$ [p.u.] & $\boldsymbol{L}_{\mathrm{r}}$ [p.u.] & $\boldsymbol{L}_{\mathrm{m}}[\mathrm{p} . \mathrm{u}]$ & $\boldsymbol{H}[\mathrm{s}]$ \\
\hline 575 & 1.5 & 157.08 & 0.02 & 0.007 & 0.171 & 0.005 & 0.156 & 2.9 & 5.04 \\
\hline
\end{tabular}

\subsection{Verification of the Calculation Method for Equivalent Inertia Time Constant of DFIG}

In the above IEEE9-node simulation system, a sudden load increase of $20 \mathrm{MW}$ was set at the position shown in Figure 4 at $t=20 \mathrm{~s}$ to simulate the system frequency transient when the active power 
was short. Through simulation, the ratio of $\Delta \omega_{\mathrm{r}}$ to $\Delta \omega_{\mathrm{s}}\left(\Delta \omega_{\mathrm{r}} / \Delta \omega_{\mathrm{s}}\right)$ during the inertial response of the DFIG is obtained, and then the simulation value of $H_{\text {eqDFIG }}$ is obtained.

In order to verify the correctness of the calculation results, the simulation results of $H_{\text {eqDFIG }}(t)$ in the process of system frequency transients caused by active power shortage are compared with the calculation results. The simulation conditions are $K_{d f}=6, K_{i f}=6, T=0.1 \mathrm{~s}$. Figure 5 is the curve of the inertial response $H_{\text {eqDFIG }}$ produced by the DFIG when the power is insufficient when the wind speed is $8 \mathrm{~m} / \mathrm{s}$ and the time of failure $\mathrm{t}=20 \mathrm{~s}$. It can be seen that the calculated value is consistent with the simulated value, which proves the correctness of the calculated result. Unlike ordinary synchronous generators, which have a constant inertia time constant, the equivalent inertia time constant of the DFIG has time-varying characteristics.

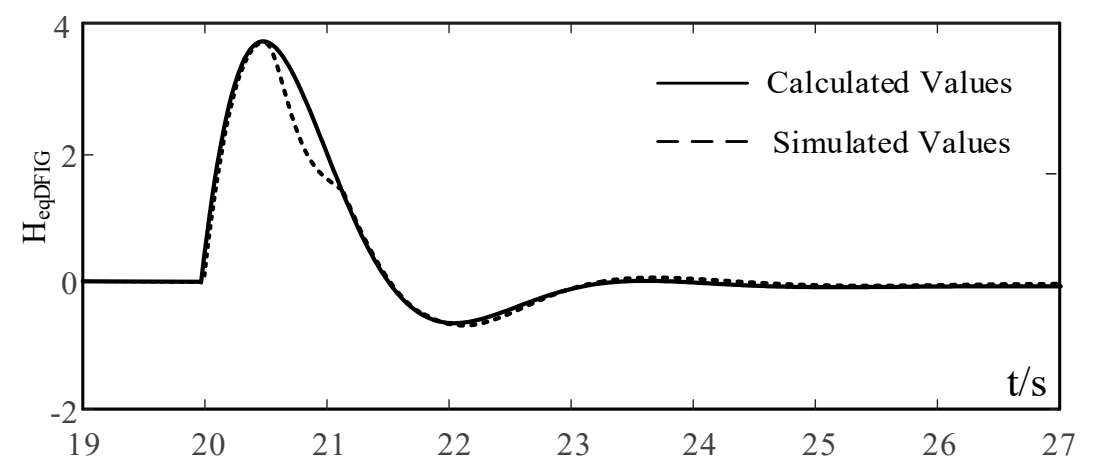

Figure 5. Comparison of calculated values and simulated values of $H_{\text {eqDFIG. }}$

Because the change rate of the system frequency is tremendous when the system disturbance occurs, the $H_{e q D F I G}$ at the initial moment of the inertial response quickly rises to a larger initial value. At that time, the DFIG releases the rotor kinetic energy, and the rotor speed drops. Moreover, when the change speed of the system frequency is higher than the change speed of the rotor speed of the DFIG, $\Delta \omega_{\mathrm{r}} / \Delta \omega_{\mathrm{s}}$ decreases. Therefore, $H_{e q D F I G}$ gradually decreases from a larger initial value. Then, the inertial response of the SFPD controller slows down the system frequency change rate, and DFIG is still in the rotor kinetic energy release stage, so $\Delta \omega_{\mathrm{r}}$ continues to increase. Then, $\Delta \omega_{\mathrm{r}} / \Delta \omega_{\mathrm{s}}$ increases instead, so $H_{\text {eqDFIG }}$ has a rising process. Then, the control effect of the speed controller becomes more evident with the increase of $\Delta \omega_{\mathrm{r}}$, and the DFIG starts to restore the speed. As the system frequency gradually recovers, the inertial response process also ends. $H_{e q D F I G}$ transitions to a minimal steady-state value after small fluctuations.

\subsection{Verification of Power System Frequency Response Model}

This section uses the detailed nonlinear simulation model based on the Simulink module as shown in Figure 4 to verify the accuracy of the established reduced-order power system frequency response model. The reduced-order power system frequency response model parameters of Figure 4 are calculated as shown in Table 3. The wind farm contains 90 DFIGs, which is equivalent to a DFIG with a rated capacity of $150 \mathrm{MW}$. The wind generation penetration in the system is $33.33 \%$. The load-shedding ratio of DFIG is $10 \%$. The wind speed is $9 \mathrm{~m} / \mathrm{s}$.

We supposed that the system load Load1 power suddenly increases at $t=50 \mathrm{~s}$. The parameter values of the load sudden-increased power and SFPD frequency regulation control parameters were respectively changed for comparison and simulation. The simulation case includes three scenarios shown in Table 4. Scenario 1 and scenario 2 maintain the SFPD frequency regulation control parameters $K_{i f}$ and $K_{d f}$ unchanged and change the load sudden-increased power $\Delta P_{L}$. Scenario 3 and scenario 2 maintain the load burst power $\Delta P_{L}$ unchanged and change the SFPD frequency regulation control parameters $K_{i f}$ and $K_{d f}$ unchanged. 
Table 3. Power system frequency response model parameters.

\begin{tabular}{ccc}
\hline Classification & Parameter & Value \\
\hline \multirow{3}{*}{ Synchronous generator } & Droop coefficient of steam turbine $R$ & 0.05 \\
& The time constant of steam turbine reheater $T_{R}$ & $10 \mathrm{~s}$ \\
& The proportion of output power of high-pressure boiler $F_{H}$ & 0.28 \\
The mechanical power gain factor $K_{m}$ & 1 \\
\hline \multirow{2}{*}{ DFIG } & The initial speed at $10 \%$ load reduction $\omega_{\text {r0_del }}$ & 1.0656 p.u. \\
& The inherent inertia time constant of the rotor $H$ & $5.04 \mathrm{~s}$ \\
& The partial conductance of electromagnetic power to & 0.78 \\
& speed $3 k_{\text {del }} \omega^{2}$ ro_del & -0.3572 \\
\hline
\end{tabular}

Table 4. Frequency response model simulation scenario.

\begin{tabular}{cccc}
\hline Classification & $\boldsymbol{\Delta P}_{\boldsymbol{L}}[\mathbf{M W}]$ & $\boldsymbol{K}_{\boldsymbol{i f}}$ & $\boldsymbol{K}_{\boldsymbol{d f}}$ \\
\hline Scenario 1 & 20 & 0 & 0 \\
Scenario 2 & 20 & 5 & 5 \\
Scenario 3 & 25 & 5 & 5 \\
\hline
\end{tabular}

In scenario 1, the time, frequency and steady-state frequency deviation of the system frequency reaching the lowest point in the Simulink nonlinear simulation model are $54.23 \mathrm{~s}, 49.657 \mathrm{~Hz}$ and $-0.178 \mathrm{~Hz}$, respectively. The active power increment of DFIG is 0.0054 p.u. Based on Equation (37), the analytical calculation model system frequency reaches the lowest point time, frequency and steady-state frequency deviation are $54 \mathrm{~s}, 49.661 \mathrm{~Hz}$ and $-0.18 \mathrm{~Hz}$, respectively, and the wind turbine active power increment is 0.0057 p.u. Combined with Figure $6 a, b$, it can be seen that the frequency response characteristics obtained from the Simulink nonlinear simulation model and the analytical calculation model based on (37) under scenario 1 are in good agreement with the active transient characteristics of the DFIG.

In scenario 2, the time, frequency and steady-state frequency deviation of the system frequency reaching the lowest point in the Simulink nonlinear simulation model are $54.25 \mathrm{~s}, 49.587 \mathrm{~Hz}$ and $-0.214 \mathrm{~Hz}$, respectively. The fan active power increment is 0.0065 p.u. Based on Equation (37), the analytical calculation model system frequency reaches the lowest point time, and frequency and steady-state frequency deviation are $54 \mathrm{~s}, 49.599 \mathrm{~Hz}$ and $-0.216 \mathrm{~Hz}$, respectively. The fan active power increment is 0.0068 p.u. Combined with Figure $6 c, d$, it can be seen that the frequency response characteristics obtained from the Simulink nonlinear simulation model and the analytical calculation model based on Equation (37) in Scenario 2 are in good agreement with the active transient characteristics of the wind turbine.

In Scenario 3, the time, frequency and steady-state frequency deviation of the system frequency reaching the lowest point in the Simulink nonlinear simulation model are $53.75 \mathrm{~s}, 49.691 \mathrm{~Hz}$ and $-0.206 \mathrm{~Hz}$, respectively. The fan active power increment is 0.017 p.u. Based on Equation (37), the analytical calculation model system frequency reaches the lowest point time, frequency and steady-state frequency deviation are $54 \mathrm{~s}, 49.696 \mathrm{~Hz}$ and $-0.208 \mathrm{~Hz}$ respectively. The fan active power increment is 0.018 p.u. Combining Figure $6 \mathrm{e}, \mathrm{f}$, it can be seen that the frequency response characteristics obtained from the Simulink nonlinear simulation model and the analytical calculation model based on Equation (37) under Scenario 3 are in good agreement with the active transient characteristics of the wind turbine.

Based on the above analysis, it can be seen that the nonlinear simulation model based on Simulink and the frequency response model based on Figure 3 have a high degree of agreement in different scenarios. By comparing Scenario 2 and Scenario 3, it can be seen that when the frequency regulation control parameter is fixed, the system frequency deviation increases when the load sudden-increased power increases. By comparing Scenario 1 and Scenario 2, it can be seen that when the load 
sudden-increased power remains unchanged, the steady-state deviation of the system frequency is reduced after DFIG participates in the frequency regulation compared to when DFIG does not add SFPD frequency regulation control. Moreover, the frequency drop speed is reduced.

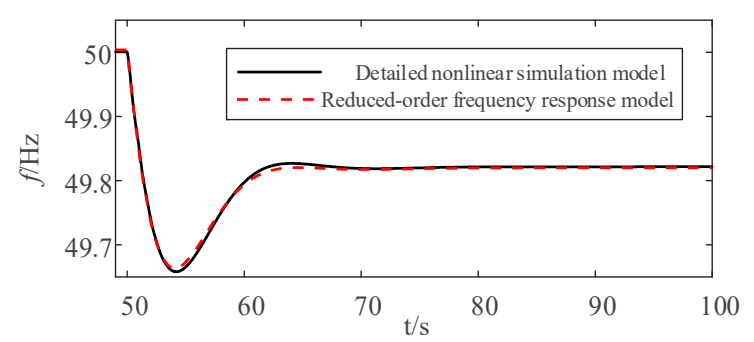

(a)System frequency curve of scenario 1

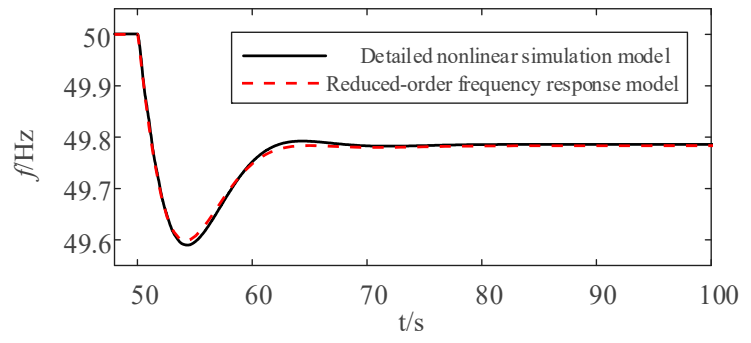

(c)System frequency curve of scenario 2

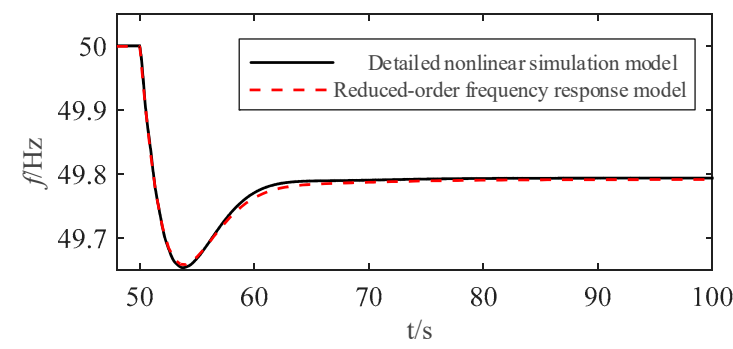

(e)System frequency curve of scenario 3

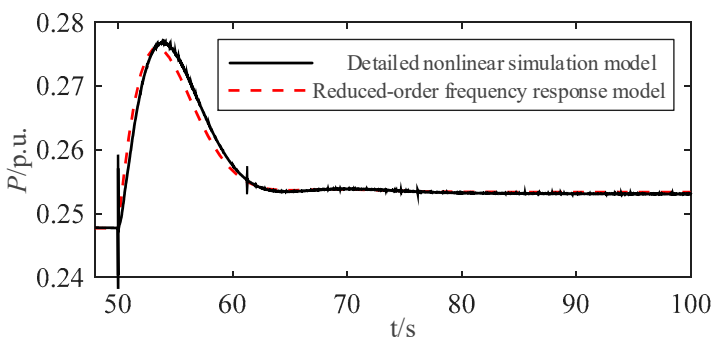

(b) Active power curve of DFIG in scenario 1

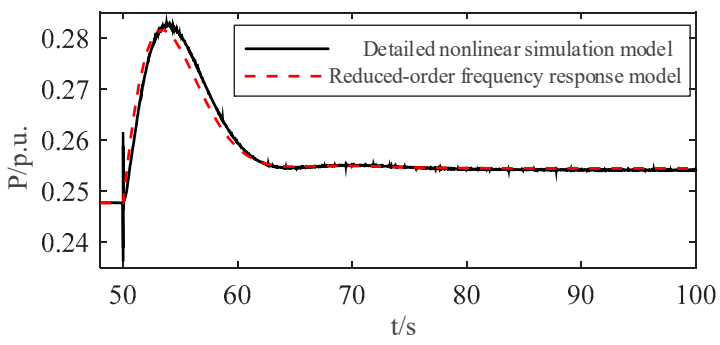

(d) Active power curve of DFIG in scenario 2

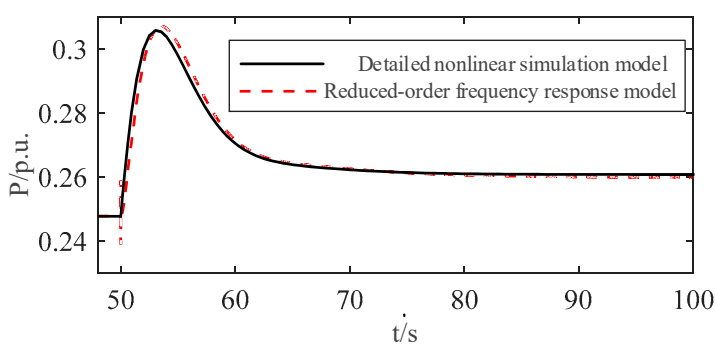

(f) Active power curve of DFIG in scenario 3

Figure 6. Comparison of calculated values and simulated values of $H_{\text {eqDFIG; }}$ (a) system frequency curve of scenario 1; (b) active power curve of DFIG in scenario 1; (c) system frequency curve of scenario 2; (d) active power curve of DFIG in scenario 2; (e) system frequency curve of scenario 3; (f) active power curve of DFIG in scenario 3.

\subsection{Verification of the Maximum Wind Generation Penetration under Different $K_{d f}$}

We supposed that the system load Load1 power suddenly increases at $t=50 \mathrm{~s}$. The parameter values of the load sudden-increased power and SFPD frequency regulation control parameters were respectively changed for comparison and simulation. The simulation case includes three scenarios shown in Table 5. The maximum wind generation penetration in the system can be calculated by Equation (31) are $16.67 \%, 18.09 \%$, and $19.77 \%$, respectively.

Table 5. Simulation scenario under different $K_{d f}$.

\begin{tabular}{ccccc}
\hline Classification & $\boldsymbol{\Delta} \boldsymbol{P}_{\mathbf{L}} / \mathbf{S}_{\mathbf{B}}$ & $\boldsymbol{d} \%$ & $\boldsymbol{K}_{\text {if }}$ & $\boldsymbol{K}_{\boldsymbol{d f}}$ \\
\hline Scenario 1 & $1 / 15$ & 10 & 2 & 0 \\
scenario 2 & $1 / 15$ & 10 & 2 & 5 \\
Scenario 3 & $1 / 15$ & 10 & 2 & 10 \\
\hline
\end{tabular}

The detailed nonlinear simulation model based on Simulink verifies the accuracy of the calculated maximum wind generation penetration through time-domain simulation. When the maximum wind 
generation penetration is $16.67 \%, 18.09 \%$, and $19.77 \%$, the number of wind farms in the time domain simulation model shown in Figure 4 contains 38, 41, and 44 DFIGs, respectively. The power of Load4 is $20.5 \mathrm{MW}, 21.9 \mathrm{MW}$, and $23.25 \mathrm{MW}$, respectively. When $\mathrm{t}=50 \mathrm{~s}$, the load sudden change power is $24.255 \mathrm{MW}, 24.545 \mathrm{MW}$, and $24.878 \mathrm{MW}$, respectively. Compare the time-domain simulation of three extreme scenarios of the wind power ratio. Figure 7 shows the system frequency response curve. Under different primary frequency regulation control parameters, the system frequency stabilizes back to around $49.8 \mathrm{~Hz}$ after transient disturbance. The steady-state frequency deviation is restricted to the maximum allowable deviation value of $0.2 \mathrm{~Hz}$, and the frequency change rate is restricted to $0.05 \mathrm{~Hz} / \mathrm{s}$. The simulation results verify the accuracy of the calculated maximum wind generation penetration. By comparing the simulation results under different frequency-regulation control coefficient scenarios $K_{d f}$, it can be seen that the maximum wind generation penetration is smaller without droop frequency-regulation control of DFIG $\left(K_{d f}=0\right)$. With the addition of droop control to wind power, the maximum wind generation penetration is increased. Moreover, as the droop control coefficient $K_{d f}$ of DFIG increases, the maximum wind generation penetration grows. This is due to the increase in the active power contribution of DFIGs with droop control during the primary frequency regulation stage during the frequency disturbance of the system. When $K_{d f}$ increases from 0 to 10 , the maximum wind generation penetration increases by about $3 \%$.

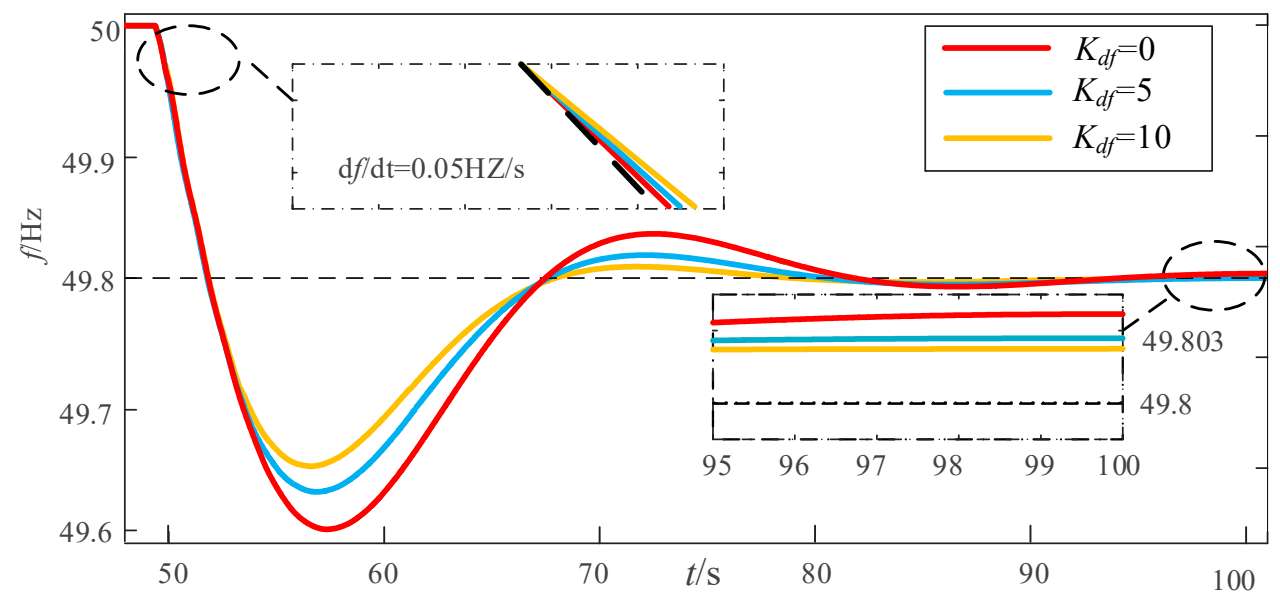

Figure 7. Simulation result of the frequency response under different $K_{d f}$.

\subsection{Verification of the Maximum Wind Generation Penetration under Different $K_{\text {if }}$}

We supposed that the system load Load1 power suddenly increases at $t=50$ s. The parameter values of the load sudden-increased power and SFPD frequency regulation control parameters were respectively changed for comparison and simulation. The simulation case includes three scenarios shown in Table 6. The maximum wind generation penetration that can be calculated by Equation (31) are $17.21 \%, 18.01 \%$, and $18.99 \%$, respectively.

Table 6. Simulation scenario under different $K_{\text {if. }}$

\begin{tabular}{ccccc}
\hline Classification & $\boldsymbol{\Delta} \boldsymbol{P}_{\mathbf{L}} / \mathbf{S}_{\mathbf{B}}$ & $\boldsymbol{d} \boldsymbol{\%}$ & $\boldsymbol{K}_{\text {if }}$ & $\boldsymbol{K}_{\boldsymbol{d f}}$ \\
\hline Scenario 1 & $1 / 15$ & 10 & 0 & 2 \\
Scenario 2 & $1 / 15$ & 10 & 5 & 2 \\
Scenario 3 & $1 / 15$ & 10 & 10 & 2 \\
\hline
\end{tabular}

The detailed nonlinear simulation model based on the Simulink module verifies the accuracy of the calculated maximum wind generation penetration through time-domain simulation. When the maximum wind generation penetration is $17.21 \%, 18.01 \%$, and $18.99 \%$, the numbers of DFIGs in the time domain simulation model, shown in Figure 5, is 39, 41, and 42, respectively. The power of 
Load4 is 20.8 MW, 21.05 MW, and 22.95 MW. When $\mathrm{t}=50 \mathrm{~s}$, the sudden load power is $21.88 \mathrm{MW}$, 24.5 MW, and 24.52 MW. Time-domain simulation is performed on several extreme scenarios of the wind power ratio. Figure 8 shows the system frequency response curve. In different $K_{i f}$ scenarios, the system frequency stabilized back to around $49.8 \mathrm{~Hz}$ after transient disturbance. The steady-state frequency deviation is restricted to the maximum allowable deviation value of $0.2 \mathrm{~Hz}$, and the frequency change rate is restricted to $0.05 \mathrm{~Hz} / \mathrm{s}$. The above simulation results verify the accuracy of the calculated maximum wind generation penetration of wind power. By comparing the simulation results under different virtual inertia control coefficient scenarios $K_{d f}$, it can be seen that the maximum wind generation penetration is smaller without virtual inertia control of DFIG $\left(K_{d f}=0\right)$. With the addition of virtual inertia control to wind power, the maximum wind generation penetration has been increased, and as the wind power virtual inertia control coefficient $K_{i f}$ increases, the maximum wind generation penetration grows. This is because the DFIG can release more rotor kinetic energy during the frequency disturbance of the system, which increases the contribution to the inertial response process of the system. When $K_{i f}$ increases from 0 to 10, the maximum wind generation penetration increases by about $1.9 \%$. Based on this, it can be concluded that the additional virtual inertia control of DFIG will promote wind power consumption to a certain extent.

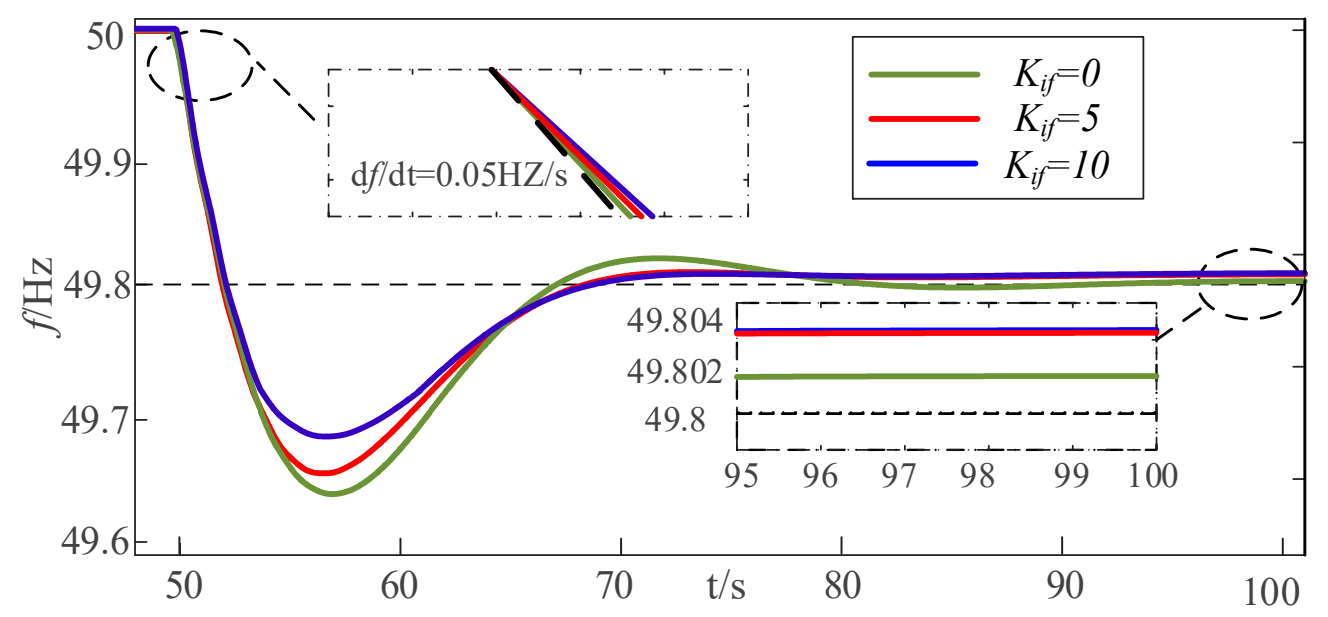

Figure 8. Simulation result of the frequency response under different $K_{i f}$.

\section{Conclusions}

This paper studies the maximum wind generation penetration under wind power frequency-regulation control and system frequency constraints. Firstly, the calculation method of the equivalent inertia time constant of the DFIG with frequency regulation control is given. Unlike the invariable inertia time constant that synchronous generators have, the equivalent inertia time constant of the DFIG has a multistage time-varying characteristic expressed as a transfer function. Then, a frequency response model of the power system with SFPD control of DFIG is established. The influence of wind power connected to the system on frequency stability is mainly due to the addition of a primary frequency regulation control loop while affecting the equivalent inertia time constant of the system. Next, the analytical method is used to solve the maximum wind generation penetration under the frequency constraint. The main factors affecting the maximum wind generation penetration are the frequency regulation control coefficient of the DFIG, the level of load change, and the proportion of deloaded. Finally, the simulation analysis verifies the correctness of the results and proves that the participation of wind power in frequency regulation control will effectively promote wind power consumption. Compared with wind power that does not participate in frequency regulation, the maximum wind generation penetration when wind power is controlled by additional frequency regulation is effectively increased. Moreover, when the frequency regulation control parameter droop control gain and virtual inertia control gain of the DFIG are larger, the maximum wind generation 
penetration is higher. How to further apply the method to more different types of renewable energy such as photovoltaics and other types of wind turbines will be the focus of future work.

Author Contributions: The authors confirm their contributions to the paper as follows: M.Q. and F.T. proposed the idea and wrote the paper; F.L. and D.L. revised the manuscript; N.D. and B.H. reviewed the results and approved the final version of the manuscript. All authors have read and agreed to the published version of the manuscript.

Funding: This paper study was funded by the National Natural Science Fund Program of China (grant number 51977157).

Acknowledgments: We sincerely thank the editor and the anonymous reviewers of the paper for their kind support. We also want to thank the Grid Corporation for providing relevant information and data.

Conflicts of Interest: The authors declare no conflict of interest.

\section{Nomenclature}

\section{Parameters}

$\psi_{d s}, \psi_{q s} \quad$ the d-axis and q-axis component of the stator flux linkage of DFIG

$\psi_{d r}, \psi_{q r} \quad$ the d-axis and $\mathrm{q}$-axis component of the rotor flux linkage of DFIG

$i_{d r}, i_{q r} \quad$ the d-axis and q-axis component of the rotor current of DFIG

$L_{m}$

$L_{s}, L_{r}$

$p$

$H_{D F I G}$

$K_{i v}$

$K_{p v}$

$k_{\text {del }}$

$\omega_{r 0}$

$K_{d f}$

$T$

$K_{d f}$

$T_{\max }, T_{\min }$

$\omega_{\mathrm{s} 0}$

the mutual inductance between the stator and rotor windings of DFIG

the self-inductance of the stator winding and the rotor winding of DFIG

the number of generator pole pairs of DFIG

the inherent inertia time constant of the DFIG

the integral coefficient of the speed controller

the proportional coefficient of the speed controller

the derating power tracking coefficient of DFIG

the initial value of the rotor angular velocity of DFIG

the proportional coefficient of the droop control link

the time constant of the low-pass filter

the proportional coefficient of the droop control link

the maximum and minimum reference torques that the speed controller can output.

the initial synchronous angular velocity of the system

$J_{D F I G}$

$\omega_{\text {nom }}$

the inherent moment of inertia of the DFIG

$\mathrm{S}_{\mathrm{N}}$

$H$

the rated angular velocity of the DFIG

the rated capacity of the DFIG

the equivalent inertia time constant of synchronous generator set after equivalent calculation

the droop coefficient of the governor

$T R$

$\mathrm{FH}$

the time constant of the turbine reheater

the proportion of the output power of the high-pressure boiler

$K_{m}$

the mechanical power gain factor

$D$

the load damping coefficient

$S_{B} \quad$ the reference capacity of the system

$S_{i} \quad$ the rated capacity of the $i$-th synchronous machine

$H_{i} \quad$ the inertia time constant of the $i$-th synchronous machine

$R_{i} \quad$ the governor difference coefficient of the $i$-th synchronous machine

$S_{j} \quad$ the rated capacity of the $j$-th wind turbine

$n^{\prime}, m \quad$ the number of synchronous machines and wind turbines

$\rho \quad$ the air density

$S \quad$ the area swept by the wind turbine blade

$\mathrm{v} \quad$ the wind speed

$\lambda$ the blade tip speed ratio

$\beta \quad$ the pitch angle

$d \% \quad$ the load reduction ratio 


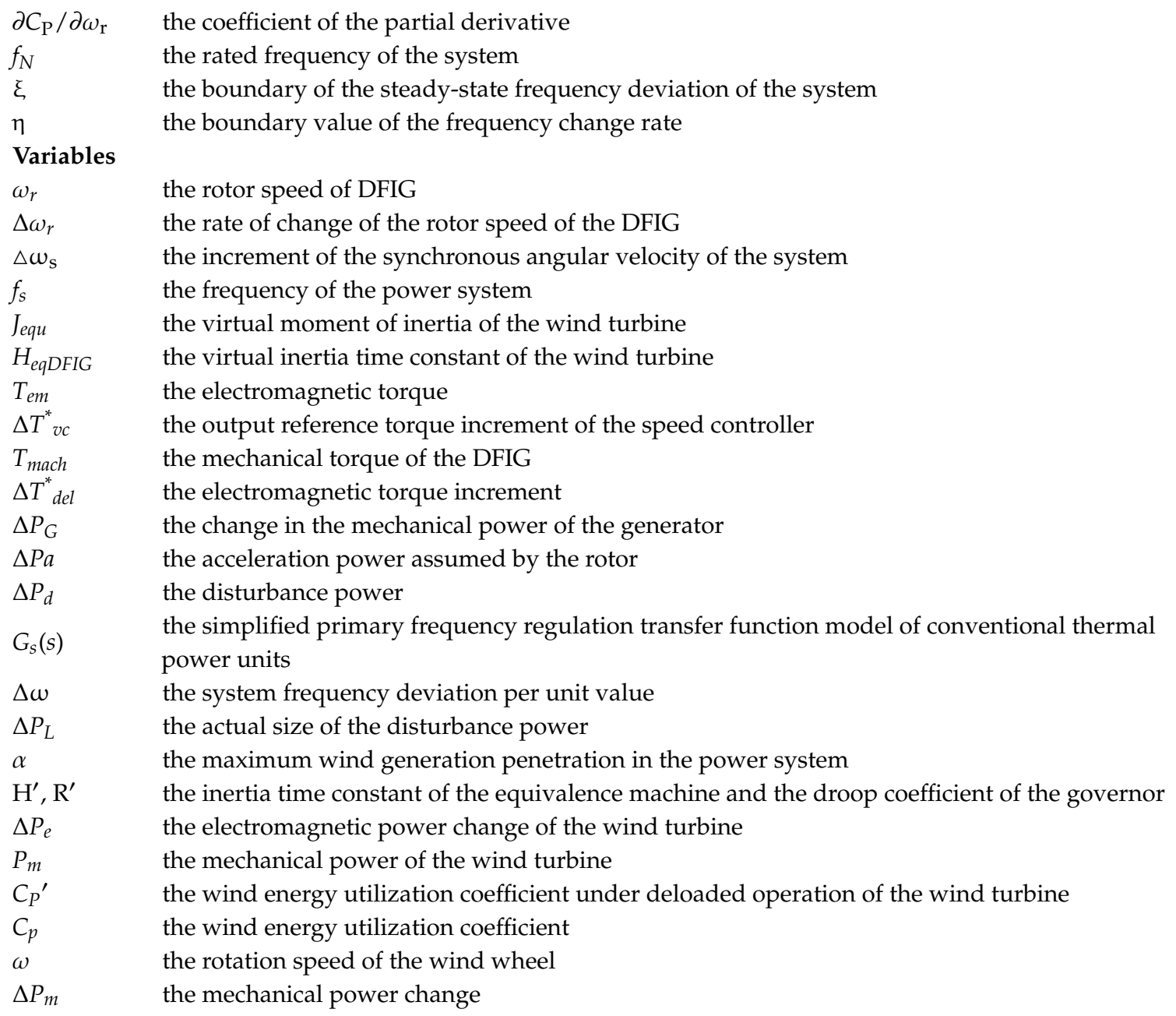

\section{References}

1. Garmroodi, M.; Verbič, G.; Hill, D.J. Frequency Support from Wind Turbine Generators with a Time-Variable Droop Characteristic. IEEE Trans. Sustain. Energy 2018, 9, 676-684. [CrossRef]

2. Global Wind Report 2018. Available online: https:/gwec.net/global-wind-report-2018 (accessed on 15 March 2019).

3. Wang, Y.; Meng, J. Control of PMSG-Based Wind Turbines for System Inertial Response and Power Oscillation Damping. IEEE Trans. Sustain. Energy 2015, 6, 565-574. [CrossRef]

4. Wu, L.; Infield, D. Power system frequency management challenges-A new approach to assessing the potential of wind capacity to aid system frequency stability. IET Renew. Power Gener. 2014, 8, 733-739. [CrossRef]

5. Shen, H.; Liang, J.; Dai, H.Z. Calculation of Wind Farm Penetration Based On Power System Transient Stability Analysis. Power Grid Technol. 2002, 8, 8-11.

6. Zhao, S.S.; Zhou, Q.Y.; Zhao, Q. Study on the maximum wind power access ratio considering frequency constraints. Chin. J. Electr. Eng. 2018, 38, 24-31.

7. Schlueter, R.A.; Park, G. A modified unit commitment and generation control for utilities with large wind generation penetrations. IEEE Trans. Power Appar. Syst. 1985, 104, 1630-1636. [CrossRef]

8. Liao, P.; Li, X. A Survey on Calculation Methods of Wind Power Penetration Limit. Power Syst. Technol. 2008, 10, 50-53.

9. Song, L.Q.; He, J.W.; Yan, G.X. Discussion on the penetration limit of the wind farm in the grid. Renew. Energy Resour. 2009, 3, 36-39.

10. SIEMENS. User Manual of PSS/E-30; Power Technologies Inc.: St. Louis, MO, USA, 2004. 
11. Gear, C.W. Simultaneous Numerical Solution of Differential-Algebraic Equations. IEEE Trans. Circuit Theory 1971, 18, 89-95. [CrossRef]

12. Glover, J.D.; Schweppe, F. Advanced Load Frequency Control. IEEE Trans. Power Appar. Syst. 1972, $2095-2103$. [CrossRef]

13. Khodabakhshian, A.; Golbon, N. Design of a New Load Frequency Pid Controller Using QFT. In Proceedings of the 2005 IEEE International Symposium on, Mediterrean Conference on Control and Automation Intelligent Control, Limassol, Cyprus, 27-29 June 2005; pp. 970-975.

14. Yan, R.; Saha, T.K. A new tool to estimate maximum wind power penetration level: In perspective of frequency response adequacy. Appl. Energy 2015, 154, 209-220.

15. Ghosh, S.; Kamalasadan, S.; Senroy, N. Doubly Fed Induction Generator (DFIG)-Based Wind Farm Control Framework for Primary Frequency and Inertial Response Application. IEEE Trans. Power Syst. 2015, 1, 1723-1727. [CrossRef]

16. Yan, R.; Saha, T.K. Frequency response estimation method for high wind penetration considering wind turbine frequency support functions. IET Renew. Power Gener. 2015, 9, 775-782. [CrossRef]

17. Zhang, J.; Chao, Q.; Duan, X.T. Research on the maximum accessible capacity of wind farms under dynamic constraints. Power Syst. Prot. Control 2011, 39, 62-66.

18. Lei, Y.Z. Application of Stochastic Programming Theory in the Analysis of Wind Power Grid Connection System; Electric Power Research Institute: Beijing, China, 2001; pp. 154-196.

19. Wang, M.; Qiu, C. A multiobjective optimization-based calculation framework of maximum wind power penetration limit considering system transient stability. Int. Trans. Electr. Energy Syst. 2020, e12465. [CrossRef]

20. Ellahi, M.; Abbas, G.; Khan, I.; Koola, P.M.; Nasir, M.; Raza, A.; Farooq, U. Recent approaches of forecasting and optimal economic dispatch to overcome intermittency of wind and photovoltaic (PV) systems: A review. Energies 2019, 22, 4392. [CrossRef]

21. Li, S.C.; Tang, H.Y.; Deng, C.H. Wind power penetration power limit calculation considering frequency constraints and frequency modulation of wind turbines. Power Syst. Autom. 2019, 43, 33-43.

22. De Almeida, R.G.; Castronuovo, E.D. Optimum Generation Control in Wind Parks When Carrying Out System Operator Requests. IEEE Trans. Power Syst. 2006, 21, 718-725. [CrossRef]

23. Li, S.C.; Deng, C.H. Calculation of Equivalent Virtual Inertial Time Constant of Wind Farm. Autom. Electr. Power Syst. 2016, 40, 22-29.

24. Aik, D.L.H. A general-order system frequency response model incorporating load shedding: Analytic modeling and applications. IEEE Trans Power Syst. 2006, 21, 709-717. [CrossRef]

25. Anderson, P.M.; Mirheydar, M. A low-order system frequency response model. IEEE Trans. Power Syst. 1990, 5, 720-729. [CrossRef]

26. Palm, W.J., III. Control Systems Engineering; Wiley: New York, NY, USA, 1986.

27. Murdoch, A.; Winkelman, J.R.; Javid, S.H.; Barton, R.S. Control Design and Performance Analysis of a $6 \mathrm{MW}$ Wind Turbine-Generator. IEEE Trans. Power Appar. Syst. 1983, 102, 1340-1347. [CrossRef]

28. Kundur, P.; Balu, N.J.; Lauby, M.G. Power System Stability and Control; China Electric Power Press: Beijing, China, 2001.

Publisher's Note: MDPI stays neutral with regard to jurisdictional claims in published maps and institutional affiliations.

(C) 2020 by the authors. Licensee MDPI, Basel, Switzerland. This article is an open access article distributed under the terms and conditions of the Creative Commons Attribution (CC BY) license (http://creativecommons.org/licenses/by/4.0/). 